\title{
Investigation and hazard implication of 1604 Quanzhou earthquake using modern simulation with literature intensity
}

\author{
Ming-Hsuan Yen $^{1,2}$, Yi-Wun Mika Liao ${ }^{3,4, *}$, Kuo-Fong Ma ${ }^{3,5,6}$, and Yuan-Chieh Wu ${ }^{7}$ \\ ${ }^{1}$ GFZ German Research Centre for Geosciences, Potsdam, Germany \\ ${ }^{2}$ Institute of Geosciences, University of Potsdam, Potsdam, Germany \\ ${ }^{3}$ Earthquake-Disaster \& Risk Evaluation and Management (E-DREaM) Center, National Central University, Taoyuan City, \\ Taiwan \\ ${ }^{4}$ GNS Science, Lower Hutt, New Zealand \\ ${ }^{5}$ Institute of Earth Sciences, Academia Sinica, Taipei City, Taiwan \\ ${ }^{6}$ Department of Earth Sciences, National Central University, Taoyuan City, Taiwan \\ ${ }^{7}$ Institute of Nuclear Energy Research, Atomic Energy Council, Executive Yuan, Taoyuan City, Taiwan
}

\section{Article history: \\ Received 4 August 2020 \\ Revised 3 January 2021 \\ Accepted 4 January 2021}

Keywords:

1604 Quanzhou earthquake, Taiwan

strait, Hybrid simulation

\section{Citation:}

Yen, M.-H., Y.-W. M. Liao, K.-F. Ma, and Y.-C. Wu, 2021: Investigation and hazard implication of 1604 Quanzhou earthquake using modern simulation with literature intensity. Terr. Atmos. Ocean. Sci., 32, 145-157, doi: 10.3319/TAO.2021.01.04.01

\begin{abstract}
The 1604 Quanzhou earthquake occurred offshore southeastern China in the Taiwan Strait and with magnitude estimated ranging from 7.5 to 8.0 , which is the largest earthquake observed in the low seismicity zone of the Taiwan strait for the last 400 years. According to literature, this earthquake caused several casualties and severe damage along the coast of southeastern China. Although no document reported the impact of this earthquake on Taiwan, the impact of an earthquake like the 1604 Quanzhou event is of great concern for the region considering the densely populated areas on both sides of the Taiwan Strait. In this study, we review the literature and past studies of this earthquake, and we simulate the level of ground shaking through various models based on past studies. Our results show that the 1604 Quanzhou earthquake had a magnitude of $\mathrm{M}_{\mathrm{w}} 8.1$ with maximum slip of $16-20 \mathrm{~m}$ on an asperity, and with an average stress drop of $10 \mathrm{MPa}$. The comparison of the simulation to the developed response spectra suggests that this earthquake brought a larger long period motion $(<0.4 \mathrm{~Hz})$ to Taiwan compared to that from the regional recorded crustal earthquakes. The long period motion from an earthquake in this magnitude scale warrants attention regarding seismic hazard mitigation for high-rise buildings for cities across the Taiwan Strait.
\end{abstract}

\section{INTRODUCTION}

On 29 December 1604, the Quanzhou earthquake occurred in the southeastern offshore area of Quanzhou, Fujian Province (Fig. 1) with a magnitude reported in the literature in the range of $7.5-8.0$ (Zhang 1981; Xie 1992), making it the largest earthquake in the Taiwan Strait in history. According to the sparse historical literature, the earthquake caused several casualties and severe damages in southeastern China, but there is limited information reported for the Taiwan region. The impact of an earthquake of this kind in the Taiwan Strait is of great concern for the densely populated metropolitans on both sides of the Taiwan Strait. In this study, we review the historical literature to constrain the

\footnotetext{
* Corresponding author

E-mail:yiwun@e-dream.tw
}

setting of the earthquake, and model this earthquake with hybrid waveform simulation to give the further implication on future seismic hazard assessment.

Tectonically, the Taiwan Strait is a foreland basin at the southeastern continental margin of the Eurasian plate covered by shallow sea water. Chen et al. (2016) investigated the 3-D shear velocity structure beneath the Taiwan Strait by jointly inverting Rayleigh and Love wave dispersion measurements. They showed varying crustal thicknesses from the coastal areas of China to Taiwan mountain belt. In the central part of the strait, the crustal thickness is thinnest of about $20 \mathrm{~km}$. The extensional basins, developed during the Eocene and Miocene, were also imaged as low-velocity zones. Compared to the highly active convergent region of Taiwan, the Taiwan Strait is seismically less active in the 


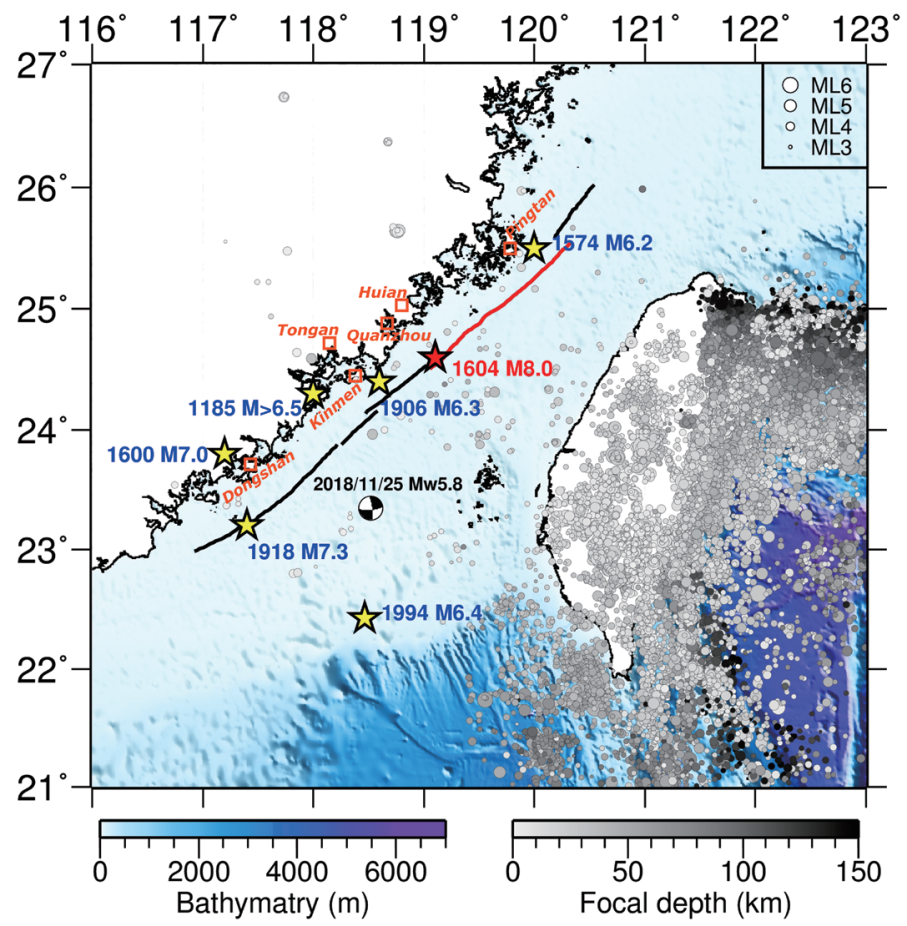

Fig. 1. The historical earthquakes (yellow asterisks) in the Taiwan Strait recorded in the literature. The gray dots indicate the seismicity near Taiwan region from CWB from 2001 to 2014 with $\mathrm{M}>3$, and that from seismic catalog of Fujian, China. Red line indicates the associated fault segment to 1604 Quanzhou earthquake, and black lines are the Fujian littoral fault (FLF) (Cheng et al. 2011; Zhang et al. 2018). The focal mechanism is a strike-slip event with magnitude of 5.8 in the Taiwan Strait from GCMT catalog.

Holocene (Fig. 1). The main pattern of fault distribution related to the occurrence of the 1604 earthquake might be associated with the offshore NNE-oriented fault, the Fujian littoral fault, FLF (Zhang et al. 2018), also known as the Binhai fault system. The FLF is an important active fault belt that controls the tectonic activity as well as the formation and evolution of the western strait (Zhan et al. 2004). Most of the earthquakes in this region have occurred in the crust and had magnitudes less than $M_{s} 5$ (Cai et al. 2015). Figure 1 shows the seismicity in southeastern China from the seismic catalog of Cai et al. (2015) for Fujian Province, and in Taiwan region from Central Weather Bureau for the years of 2001 to 2014 with $\mathrm{M}>3.0$. Within the Binhai fault system, the background seismicity is relatively low compared to Taiwan, despite several significant literature-documented historical earthquakes. Among them, the intensely destructive earthquake with a magnitude of approximately 8 in 1604 offshore Quanzhou was the largest event ever documented in this area.

In this study, we review the historical literature and the past studies for this earthquake. We then present our ground shaking simulations based on various models constrained on the information from the historical literature. Ground shaking is simulated with high-frequency and low-frequency hybrid seismic waveform modeling to the target stations of the documented damaged cities in southeast China and some stations within the Taiwan Strait. We compare the simulated ground shaking to historical intensity reports. We also com- pare simulated response spectra of the stations in the Taiwan Strait with developed response spectra from ground motion prediction equations (GMPE) of NGA-East (PEER 2015) and crustal earthquakes of Taiwan (Lin et al. 2012). In the simulation, we consider homogeneous slip and heterogeneous slip fault models with a single asperity. Given many uncertainties from the 400-year-old historical earthquake, we consider only a single asperity model for the study to give a general understanding about the differences of a homogeneous slip distribution model to a heterogeneous slip model.

\section{LITERATURE REVIEW OF THE 1604 QUANZHOU EARTHQUAKE}

According to modern compiled literature, the associated damage from the 1604 Quanzhou earthquake covered the region extending for about $1000 \mathrm{~km}$ away from the epicentral area (Xie and Cai 1985). The severely damaged regions were from near Quanzhou County (now Jinjiang area) to Xinghua County (present-day Putian area), according to the description by Xie (1992). The original China earthquake intensity scale listed its intensity from 7 to as high as 9 for the region, and we translated the description from Xie and Cai (1985) into English as follow within the double quotation marks. The city of Quanzhou experienced severe damage with intensity 9. "Buildings and other structures, including the Kaiyuan Temple East Tower and Luoyang Bridge, 
were destroyed. The ground cracked in many places, and fissures opened in Qingyuan Mountain burst with sand, water, and sulfur-smelling gas." The region of Nanan, although farther from Quanzhou, was still close to the center of the fault zone and was also identified as intensity 9. Putian and Tongan, which are to the north and center of the possible fault zone, are in the zone with intensity 8 . "The gate walls collapsed, the towers were smashed, and many urban and rural houses were destroyed. There were cracks in the streets, and water with black sand came through them.” Zhangpu, located in the southern section of the possible fault zone, was also in the intensity 8 zone, and reported many damaged and collapsed buildings. "The statue in Xingjiao Temple was damaged; Zhongjiefang and Xianyunfang fell, and a large hole opened around the Nancheng Gate, and black sand and water poured out." In the middle region farther from the fault zone, where the earthquake's intensity was 7, Anxi had deformed mountains and rivers. Fuzhou, in the north, was also reported to have intensity 7 . People there felt the strong shaking of the initial quake and continued shaking at night. "Many buildings tilted, and people who feared the walls would collapse ran out and stayed outside." Some minor damage was reported in Huian, which felt the shaking and some aftershocks. The coastal line of Pingtan subsided, according to a Pingtan County historical document.

We extrapolate/interpolate the historical intensities of the towns to the contour lines to indicate the historical intensity, which we further compare to the simulated intensity.

Since the original intensity scale described in 1604 might be different from the current model intensity scale, GAQSIQ and SAC (2008) sought to classify the historical China earthquake intensity scale to the equivalent peak ground acceleration (PGA). The reliability of this classification is uncertain, but by correlating the damage reports of historical and modern earthquakes with instrumental data, they classified the equivalent conversions of China's historical earthquake intensities to the PGA as listed in Table 1. The historical intensity scale levels greater than intensity 7 are equivalent to PGA $>90$ gal. Intensity 8 is PGA $>178$ gal; intensity 9 is PGA $>354$ gal, and intensity 10 is PGA $>708$ gal.

Although the 1604 event occurred offshore, no related damaging tsunamis were reported. However, the depth of the water in the bay is shallow, and reports noted that the local sea surface was abnormally disturbed, the water shaking sharply. Further descriptions in neighboring coastal areas include "The mountains and the seas are moving" and "There are many overturning boats" in the harbor (Huang et al. 2006).

\section{THE BINHAI FAULT AND SEISMICITY}

The Binhai fault zone is a right-lateral strike-slip fault with a thrust component. The total length is about $500 \mathrm{~km}$ (Fig. 1), and 50 to $60 \mathrm{~m}$ below sea level (Huang and Wang
2006; Huang et al. 2006). Huang and Wang (2006) divided the Binhai fault zone into four sections. (1) Pingtan's overseas section is $55 \mathrm{~km}$ long, extending to the southwest. (2) The overseas section of Quanzhou is $100 \mathrm{~km}$ long with a steep dip angle; the north middle section extends to the northeast, and the south section extends to the southwest. (3) The overseas section of Kinmen is $90 \mathrm{~km}$ long and extends to the southwest. (4) Dongshan Overseas Section is $100 \mathrm{~km}$ long. Zhang et al. (2020) also mapped strike-slip fault segments in the southwest of the Taiwan Strait by using seismic reflection profiles.

Several studies reported additional historically significant earthquakes from the Binhai fault zone, namely the $\mathrm{M}$ $>6.5$ event in $1185, \mathrm{M} \sim 6.2$ in $1574, \mathrm{M} \sim 6.2$ in $1600, \mathrm{M}$ $\sim 6.3$ in 1906, and M 7.3 in 1918, as shown in Fig. 1 (Ding et al. 1989; DEDP 1995; Guo et al. 2015), although the region is considered seismically less active. Figure 1 also shows seismicity for $\mathrm{M}>3$ from the modern observations of the seismic catalogue in the Fujian province between 2001 and 2014. The focal depth distribution is approximately between 0 and $10 \mathrm{~km}$. Few events are inland, while most of the seismicity in the region is associated with the Binhai fault zone with predominantly strike-slip faulting (Sun et al. 2012; Cai et al. 2015).

\section{CONSTRUCTION OF FAULT MODELS AND SOURCE PARAMETERS FOR GROUND MOTION SIMULATION}

Previous studies (Xie 1992; Huang et al. 2006) suggested the magnitude of the 1604 earthquake could be about M 7.5 to M 8.0, with a focal depth of about 5 to $10 \mathrm{~km}$. The estimated epicenter location is in the region of about 24.6 $-25.0^{\circ} \mathrm{N}, 118.9-119.5^{\circ} \mathrm{E}$. The focal mechanisms and the locations of this earthquake from previous studies (Zhang 1981; Wu 1988; Huang et al. 2006) are shown in Fig. 2. In this study, we consider a focal depth of $10 \mathrm{~km}$ by considering background seismicity, and for the epicenter location, we consider the study of Huang et al. (2006) (Fig. 2).

\subsection{Fault Model with Homogeneous Slip}

We consider the focal mechanisms reported from previous studies (Fig. 2), and summarize them in Table 2. The length of the fault is considered to be $250 \mathrm{~km}$ according to the scaling law of Wells and Coppersmith (1994) for $M_{w}$ 8.0. We placed the location of the fault model according to the geological fault structure. Considering the dip angles of the mechanisms in the three models and the depth of the seismogenic zone, which is $15 \mathrm{~km}$ (Cai et al. 2015), the corresponding fault widths of Models A, B, and C are 20, 18.5, and $15 \mathrm{~km}$, respectively (Table 2 ). The fault planes are divided into subfaults of $5 \mathrm{~km} \times 5 \mathrm{~km}$, and, thus, the fault models of A, B, and C have 200, 200, and 150 subfaults, 
Table 1. The conversion of intensity to peak ground acceleration (GAQSIQ and SAC 2008).

\begin{tabular}{ccc}
\hline Historical Intensity & PGA $\left(\mathbf{c m ~ s}^{-2}\right)$ & Descriptions \\
\hline 1 & & Not felt \\
2 & & Weak \\
3 & & Weak \\
4 & & Weak \\
5 & $22-44$ & Light \\
6 & $45-89$ & Strong \\
7 & $90-177$ & Very strong \\
8 & $178-353$ & Severe \\
9 & $354-707$ & Violent \\
10 & $708-1414$ & Extreme \\
\hline
\end{tabular}

$118^{\circ} \mathrm{E}$

$120^{\circ} \mathrm{E}$

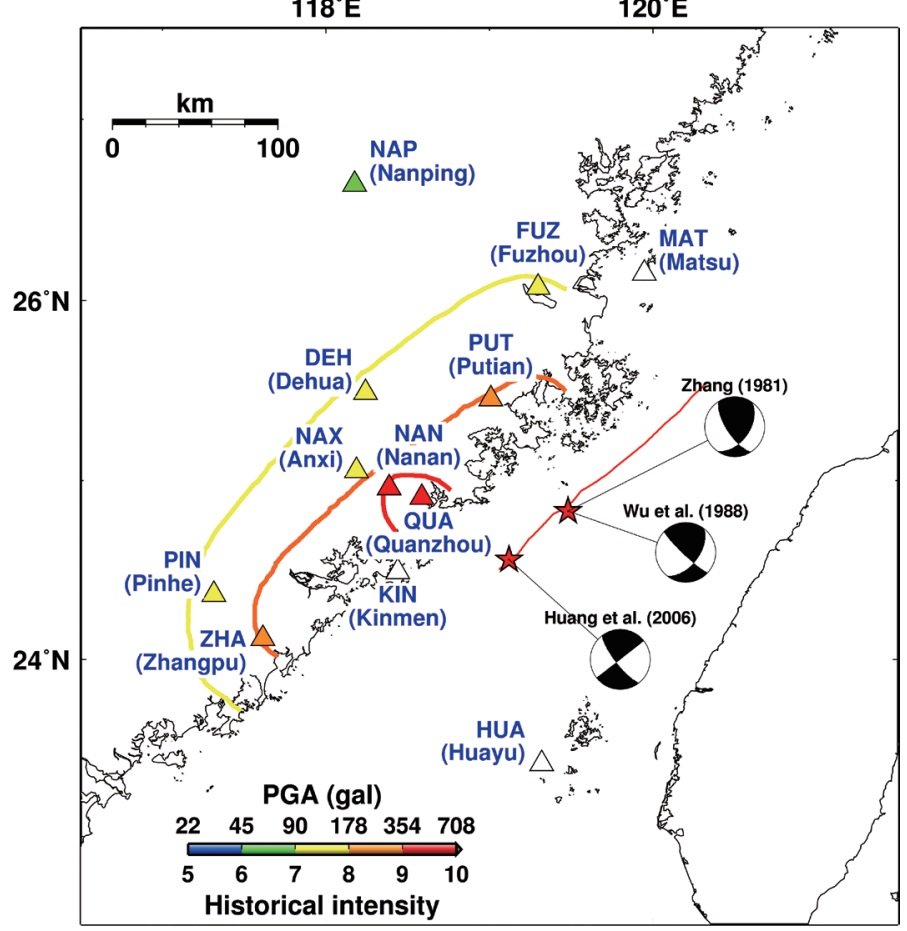

Fig. 2. The historical intensity of 1604 Quanzhou earthquake addressed by Xie (1992). The towns with the damage descriptions denoted by color triangles are shown. The red asterisks indicate the possible locations and focal mechanisms of the 1604 Quanzhou earthquake from previous studies. The possible fault segment associated with the 1604 Quanzhou earthquake is shown as red solid line, namely Binhai fault. The target stations for further seismological simulations in SE China are the stations related to the towns stated in the historical literature with intensity. The contour lines were made by the extrapolation/interpolation of the historical intensities of the towns. The contour colors indicate the historical intensity which we further compare to synthetic intensity. The open triangles are the stations within Taiwan Strait. The focal mechanisms of this earthquake from previous studies (Zhang 1981; Wu 1988; Huang et al. 2006) are also shown. 
Table 2. The parameters of the fault models with homogeneous slip.

\begin{tabular}{|c|c|c|c|c|c|c|}
\hline \multirow[b]{2}{*}{ Strike $\left(^{\circ}\right)$} & \multicolumn{2}{|c|}{ Model A } & \multicolumn{2}{|c|}{ Model B } & \multicolumn{2}{|c|}{ Model C } \\
\hline & 36 & 36 & 38 & 38 & 52 & 52 \\
\hline $\operatorname{Dip}, \delta\left(^{\circ}\right)$ & 49 & 49 & 54 & 54 & 90 & 90 \\
\hline Rake $\left({ }^{\circ}\right)$ & 150 & 150 & 171 & 171 & 166 & 166 \\
\hline Mw & 7.7 & 8.1 & 7.7 & 8.0 & 7.5 & 7.9 \\
\hline Fault length, L (km) & 250 & 250 & 250 & 250 & 250 & 250 \\
\hline Lower depth of fault, $H_{d}(\mathrm{~km})$ & 15 & 15 & 15 & 15 & 15 & 15 \\
\hline Fault width, W (km) & 20 & 20 & 18.5 & 18.5 & 15 & 15 \\
\hline Stress drop, $\Delta \sigma(\mathrm{MPa})$ & 3.0 & 10.0 & 3.0 & 10.0 & 3.0 & 10.0 \\
\hline Average slip, D (m) & 3.14 & 10.47 & 2.91 & 9.69 & 2.35 & 7.85 \\
\hline Fault area, $\mathbf{S}\left(\mathbf{k m}^{2}\right)$ & 5000 & 5000 & 4625 & 4625 & 3750 & 3750 \\
\hline $\mathbf{M}_{0}(\mathbf{N} \cdot \mathbf{m})$ & $4.71 \mathrm{E}+20$ & $1.57 \mathrm{E}+21$ & $4.03 \mathrm{E}+20$ & $1.34 \mathrm{E}+21$ & $2.64 \mathrm{E}+20$ & $8.83 \mathrm{E}+21$ \\
\hline Seismic moment of subfault $(\mathrm{N} \cdot \mathrm{m})$ & $2.36 \mathrm{E}+18$ & $7.85 \mathrm{E}+18$ & $2.02 \mathrm{E}+18$ & $6.70 \mathrm{E}+18$ & $1.76 \mathrm{E}+18$ & $5.89 \mathrm{E}+18$ \\
\hline
\end{tabular}

respectively (Fig. 2). We assume average stress drops of 3 and $10 \mathrm{MPa}$, as the values most frequently obtained in earthquakes (Kanamori and Anderson 1975; Allmann and Shearer 2009), were considered for each fault model. Thus, in total, 6 models were made for the ground motion simulations.

The amount of slip on the fault was determined by using the relationship of the strike-slip fault model to stress drop as $\Delta \sigma=2 / \pi \times \mu \times \mathrm{D} / \mathrm{W}$ (Irikura and Miyake 2001; Irikura 2004), where $\Delta \sigma$ is the average stress drop, and $\mu$ is the shear modulus (set to $3 \times 10^{10} \mathrm{~Pa}$ ). With the width of the fault, $\mathrm{W}$, determined above, we estimated the average slip, $\mathrm{D}$, of the homogeneous slip model of these 6 fault models. The seismic moments $\left(\mathrm{M}_{0}\right)$ of each model were calculated using $\mathrm{M}_{0}=\mu \times \mathrm{S} \times \mathrm{D}$, where $\mathrm{S}$ is the area of the fault, and the corresponding seismic moment magnitude $\left(\mathrm{M}_{\mathrm{w}}\right)$ is obtained from $M_{w}=2 / 3 \log M_{0}-6.1$ for $M_{0}$ in Nm. The source parameters obtained for the average stress drop of 3 and $10 \mathrm{MPa}$ are listed in Table 2.

\subsection{Fault Model with Heterogeneous Slip with a Single Asperity}

For a fault model with heterogeneous slip, we consider the model with one asperity. The setting of the asperity model, we follow Irikura and Miyake (2001) and Irikura (2004) for inner and outer source parameters. The inner parameters refer to the source parameters for the asperity, such as the asperity area, the average slip and the stress drop.

We consider the area with a slip $\left(\mathrm{D}_{\mathrm{a}}\right)$ twice the average slip as asperity, and following Somerville et al. (1999) and Lee et al. (2016) the asperity area $\mathrm{Sa}$ is $22 \%$ of the total area (S) based on observations from earthquakes from California and Taiwan. Although there can be multiple asperities distributed within the fault plane, for simplification due to many uncertainties from this 400-year-old historical earthquake, we consider only a single asperity for our heterogeneous model. According to the intensity map shown in Fig. 2, we placed the asperity for each fault model near the region with largest reported intensity. For the asperity model, we only consider the case with an average stress drop of $10 \mathrm{MPa}$, as we will show later that the results for $3 \mathrm{MPa}$ underestimate the scale of intensity compared to the historical intensity distribution.

The stress drop $\left(\Delta \sigma_{\mathrm{a}}\right)$ of the asperity was scaled according to the average stress drop, $\Delta \sigma$, of $10 \mathrm{MPa}$ as $\Delta \sigma_{\mathrm{a}}=$ $\left(\mathrm{S} / \mathrm{S}_{\mathrm{a}}\right) \cdot \Delta \sigma$. With the seismic moment of the asperity (based on $\mathrm{Sa}$ and $\mathrm{Da}$ ), the corresponding source parameters for the asperity and the background area are listed in Table 3 .

\section{GROUND MOTION SIMULATION}

The seismic waveforms of the low-frequency and highfrequency components are simulated separately, and combined to obtain the broadband seismic time series and the corresponding acceleration responses in the hybrid simulation. The sampling rate of the time series is 20 points per second. The cutoff frequency in a hybrid simulation between low and high frequencies is set to be $3 \mathrm{~Hz}$ in our models, after the sensitivity test of cutoff frequency by comparing the synthetic response spectra with the GMPE predicted ones. The response spectra usually drop dramatically in $1-3 \mathrm{~Hz}$ in the high-frequency simulation due to its limit in simulation while using $1 \mathrm{~Hz}$ as the cutoff frequency. For the low frequency simulation method $(<3 \mathrm{~Hz})$, we used the FrequencyWavenumber (F-K) algorithm by Zhu and Rivera (2002). For the high frequency part $(>3 \mathrm{~Hz})$, we used the EXSIM (Stochastic Finite-Fault Ground-Motion Simulation Algorithm) (Boore 1983; Motazedian and Atkinson 2005), which 
is available on the SCEC (Southern California Earthquake Center) broadband strong motion simulation platform.

In the F-K simulation, the Green's functions were based on the subfaults of the fault models stated above. The $1-\mathrm{D}$ velocity structure in the F-K simulation was converted from 3-D P-wave and S-wave velocities in the Taiwan Strait region of Chen et al. (2016) by averaging them over depth (Table 4). The point source of the unit seismic moment of each subfault was made by dividing the total moment of each fault model with its number of subfaults (Table 2). We consider an average rupture speed of $2.4 \mathrm{~km} \mathrm{~s}^{-1}$, based on $80 \%$ of the average shear-wave velocity of $3 \mathrm{~km} \mathrm{~s}^{-1}$. A uniformly distributed variation of $\pm 0.4 \mathrm{~km} \mathrm{~s}^{-1}$ was applied to the average rupture speed of $2.4 \mathrm{~km} \mathrm{~s}^{-1}$ for the forward simulation. The source time function was set as a trapezoid with a rise time of 2.91 seconds. The rise time was calculated from the formula of rupture speed and the width of the subfault following Irikura and Miyake (2001) and Irikura (2004).

In the EXSIM simulation, the parameters for the highfrequency simulation are the stress drop, $f_{\max }$, quality factor, and the attenuation of geometrical spreading. The stress drop is considered as the same in the low-frequency simulation, and the $f_{\max }$ is $50 \mathrm{~Hz}$. Due to the lower seismic activity in the Taiwan Strait, the attenuation of geometrical spreading was set as the setting for eastern North America as the stable continent (Atkinson and Boore 1998). The quality factor is a function of frequency, $\mathrm{Q}=\mathrm{af}^{\mathrm{b}}$, with $\mathrm{a}=117$ and $\mathrm{b}$ $=0.77$, for Taiwan (Roumelioti and Beresnev 2003).

We set up target stations according to the towns named in the historical documents. Taking the historical intensity distribution proposed by Xie (1992) (Fig. 2), we consider nine stations in the coastal area of southeast China: QUA and NAN (intensity 9); PUT and ZHA (intensity 8); FUZ, DEH, NAX, and PIN (intensity 7); and NAP (intensity 6) (Table 5). In order to understand the possible ground shaking of the historical significant earthquake in the region near Taiwan, we set three more stations on the islands west offshore of Taiwan-HUA, MAT, and KIN. These three stations are in the Taiwan Strait and are used for comparison to the response spectra of NGA-East (PEER 2015), and crustal earthquakes in Taiwan (Lin et al. 2012), while the stations in southeast China related to historical intensity sites are used for simulated and historical intensity comparison.

Figure 3 shows a synthetic seismogram at the station QUA as an example from Model A (homogeneous slip with stress drop of $3 \mathrm{MPa}$ ). The PGA is obtained from the maximum value of the simulated acceleration time series from the three components. The PGA values are converted to historical earthquake intensities according to the tables listed in the China Earthquake Intensity scale (GAQSIQ and SAC 2008) and is carried out for all the historical-site stations for the comparison to the literature-reported intensities (Table 1). For the stations in the Taiwan Strait, the simulated accelerograms were furtherly converted to response spectra for the comparison to the developed acceleration response spectra from NGA-East and Taiwan crustal earthquakes.

\section{RESULTS AND DISCUSSION}

\subsection{Comparison of the Simulated Intensity to Literature Intensity}

Figures $4 \mathrm{a}$ and $\mathrm{b}$ show the comparison of the simulated intensity map (shown by stations) to the literature-stated intensity (shown by contours) for the stress drops of 3 and 10 MPa, respectively, for the homogeneous fault Models A, B, and $\mathrm{C}$. The average slips for the homogeneous models are about 2 - $3 \mathrm{~m}$ for $3 \mathrm{MPa}$, and 7 - $10 \mathrm{~m}$ for $10 \mathrm{MPa}$ fault models (Table 2). For the model with a stress drop of $3 \mathrm{MPa}$, most of the stations are with the simulated intensity 6 , much smaller than the historical intensity. Although the maximum intensity reaches 7 in all models, none of the simulated intensities can match the literature intensity. Although the factors of site amplification were not considered in the simulated intensity, the general difference in about an order less to the observed intensity, for this case, might not relate to the local site amplification. For the fault model with the stress drop of $10 \mathrm{MPa}$, the overall intensity distribution of Models A, B, and C is similar. Most of the regions have a reported intensity of 7 or higher. However, some stations further inland have simulated intensities 8 or 9 , which are higher than their corresponding historical intensities of 7 or 8 . To understand how well the simulated intensities match the reported intensities, we mark stations with comparable intensities in Fig. 4b. There are generally only about three stations with simulated intensities comparable to reported intensities from Models A, B, and C. The comparison from the fault model with homogeneous slip suggests a high stress drop of about $10 \mathrm{MPa}$ is necessary to explain the historical distributed intensity, however some inland stations are overestimated by one intensity level. This suggests a heterogeneous slip model might be necessary to explain the pattern of historical intensity map.

As the results from the $3 \mathrm{MPa}$ of homogeneous slip models underestimates the reported intensity, for heterogeneous slip models with one asperity, we consider only the case of with an average stress drop of $10 \mathrm{MPa}$. For the average stress drop of $10 \mathrm{MPa}$ with one asperity, the stress drop in the asperity is $45.5 \mathrm{MPa}$, and for the rest of the fault, it is about $7 \mathrm{MPa}$. The amount of slip in the asperity is about $16-21 \mathrm{~m}$, with the slip in the rest of the fault area of about 7 - $8 \mathrm{~m}$ (Table 3). Figure 5 shows the comparison of the simulated intensity to the reported intensities for Models A, $\mathrm{B}$, and $\mathrm{C}$, respectively. With the same average stress drop of $10 \mathrm{MPa}$ from homogeneous fault model (Fig. 4b), the one asperity model with an average stress drop of $10 \mathrm{MPa}$ (Fig. 5) shows a simulated intensity pattern more similar to the historical intensity map. It shows larger intensity for the stations near the coast close to the fault with the asperity 
Table 3. The parameters of the fault models with heterogeneous slip model of one asperity.

\begin{tabular}{c|ccc}
\hline & Model A & Model B & Model C \\
\hline $\mathrm{Mw}$ & 8.1 & 8.0 & 7.9 \\
Average stress drop $(\mathrm{MPa})$ & 10 & 10 & 10 \\
\hline \multicolumn{4}{c}{ Asperity } \\
\hline Average slip $\mathrm{D}_{\mathrm{a}}(\mathrm{m})$ & 20.94 & 19.38 & 15.70 \\
$\mathrm{~S}_{\mathrm{a}} / \mathrm{S}$ & 0.22 & 0.22 & 0.22 \\
Area $\mathrm{S}_{\mathrm{a}}\left(\mathrm{km}^{2}\right)$ & 1100 & 1017.5 & 825 \\
Width $\mathrm{W}_{\mathrm{a}}(\mathrm{km})$ & 10 & 10 & 10 \\
Seismic moment $\mathrm{M}_{0 \mathrm{a}}(\mathrm{N} \cdot \mathrm{m})$ & $6.91 \mathrm{E}+20$ & $5.92 \mathrm{E}+20$ & $3.89 \mathrm{E}+20$ \\
Stress drop $\Delta \sigma_{\mathrm{a}}(\mathrm{MPa})$ & 45.5 & 45.5 & 45.5 \\
\hline \multicolumn{4}{c}{} \\
\hline Average slip $\mathrm{D}_{\mathrm{b}}(\mathrm{m})$ & 7.51 & 6.91 & 7.74 \\
Area $\mathrm{S}_{\mathrm{b}}\left(\mathrm{km}^{2}\right)$ & 3900 & 3607.5 & 2925 \\
Seismic moment $\mathrm{M}_{0 \mathrm{~b}}(\mathrm{~N} \cdot \mathrm{m})$ & $8.79 \mathrm{E}+20$ & $7.48 \mathrm{E}+20$ & $4.94 \mathrm{E}+20$ \\
\hline
\end{tabular}

Table 4. 1-D velocity structure for the interval of every $5 \mathrm{~km}$ of the Taiwan Strait estimated from 3D velocity tomography of Chen et al. (2016).

\begin{tabular}{ccc}
\hline Depth $(\mathbf{k m})$ & $\mathbf{V s}\left(\mathbf{k m ~ s}^{\mathbf{1}}\right)$ & $\mathbf{V} \mathbf{p}\left(\mathbf{k m ~ s}^{\mathbf{1}}\right)$ \\
\hline 0 & 3.08 & 5.33 \\
5 & 3.18 & 5.51 \\
10 & 3.43 & 5.94 \\
15 & 3.52 & 6.10 \\
20 & 3.68 & 6.37 \\
25 & 3.80 & 6.59 \\
30 & 3.93 & 6.80 \\
35 & 4.04 & 6.99 \\
40 & 4.13 & 7.16 \\
45 & 4.23 & 7.32 \\
50 & 4.32 & 7.48 \\
55 & 4.40 & 7.63 \\
60 & 4.50 & 7.79 \\
65 & 4.60 & 7.96 \\
70 & 4.72 & 8.17 \\
\hline
\end{tabular}

Table 5. The information of target stations. Stations (HUA, MAT, and KIN) which did not have historical records are compared the acceleration spectrum. Other stations with historical intensity are compared with the synthetic intensity.

\begin{tabular}{c|ccc}
\hline stations & latitude & Longitude & Historical intensity \\
\hline HUA & 23.410 & 119.320 & - \\
MAT & 26.152 & 119.946 & - \\
KIN & 24.491 & 118.439 & - \\
QUA & 24.906 & 118.587 & 9 \\
NAN & 24.960 & 118.386 & 9 \\
PUT & 25.454 & 119.008 & 8 \\
NAX & 25.056 & 118.186 & 7 \\
ZHA & 24.117 & 117.614 & 8 \\
FUZ & 26.075 & 119.297 & 7 \\
DEH & 25.491 & 118.241 & 7 \\
PIN & 24.364 & 117.315 & 7 \\
NAP & 26.642 & 118.176 & 6 \\
\hline
\end{tabular}


(a)
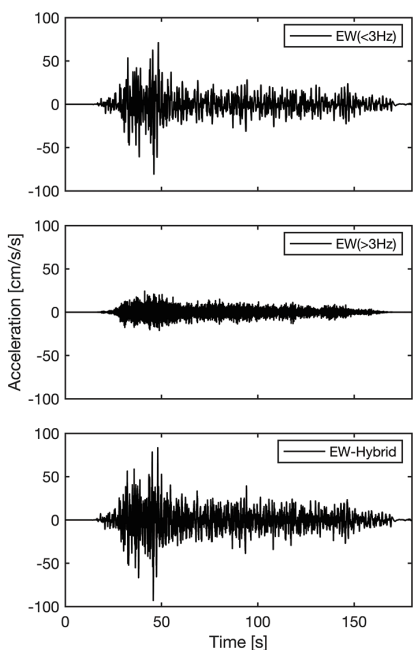

(b)

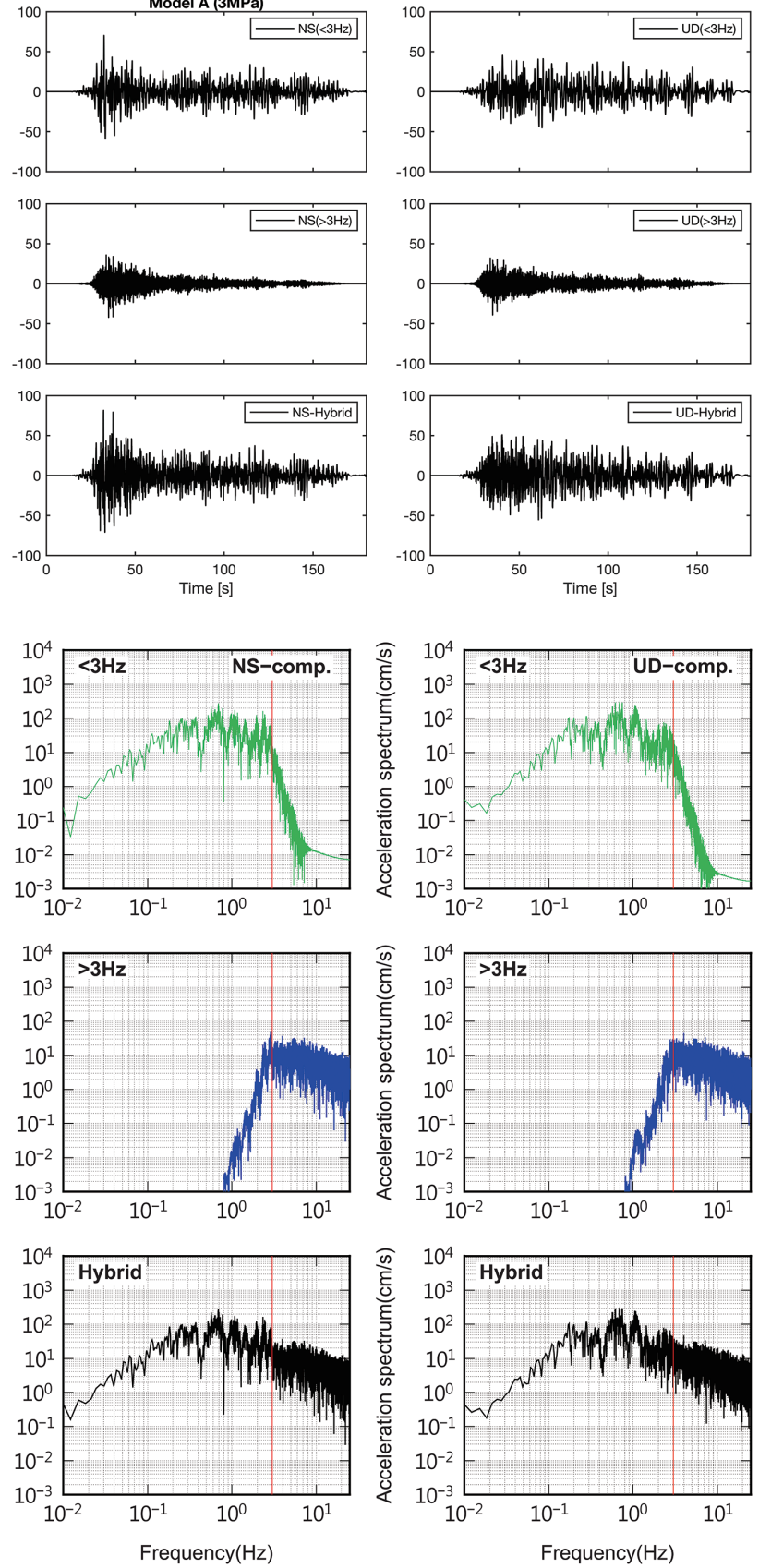

Fig. 3. An example shows the three components low frequency $(<3 \mathrm{~Hz})$ and high frequency $(>3 \mathrm{~Hz})$ hybrid (a) waveforms, and (b) acceleration spectra for the station of Quanzhou (QUA) for an average of stress drop $3 \mathrm{MPa}$. 
(a)
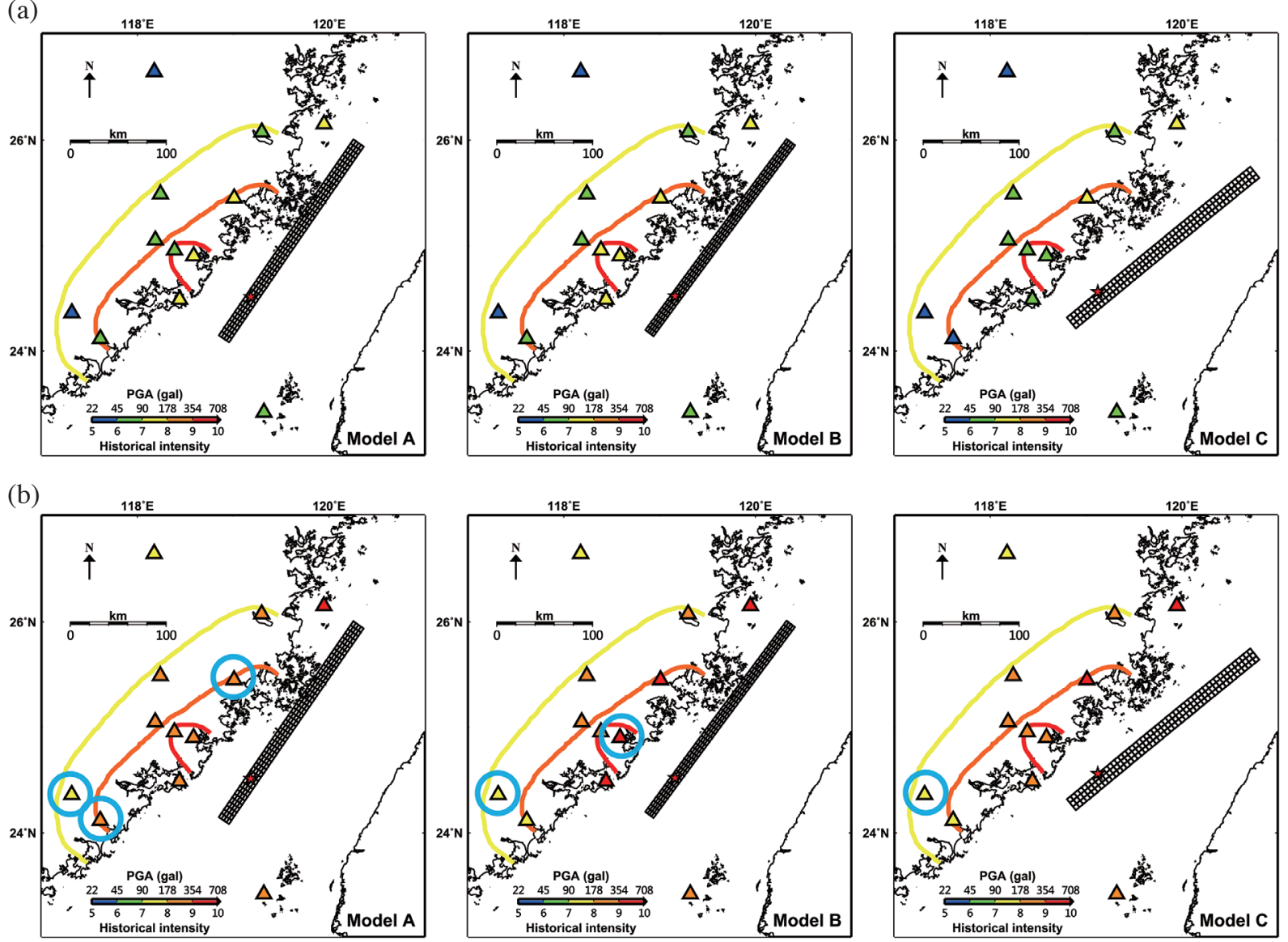

Fig. 4. The fault models with homogeneous slip, and comparison of the simulated intensity to literature intensity with focal mechanisms of Model A with 200 subfaults, Model B with 200 subfault, and Model C with 150 subfaults. The red asterisk indicates the epicenter of 1604 Quanzhou earthquake of from Huang et al. (2006). The contour lines present the historical intensity distribution with the comparison of the simulated intensity for the stations (tringles with color correspond to the intensity) on the towns literature stated intensity for stress drop of (a) $3 \mathrm{MPa}$ and (b) $10 \mathrm{MPa}$, respectively. The stations with a blue circle around are those who match the value of the literature intensity shown in Fig. 2 . The corresponding historical intensity with PGA values for target stations in Taiwan Strait are also shown.
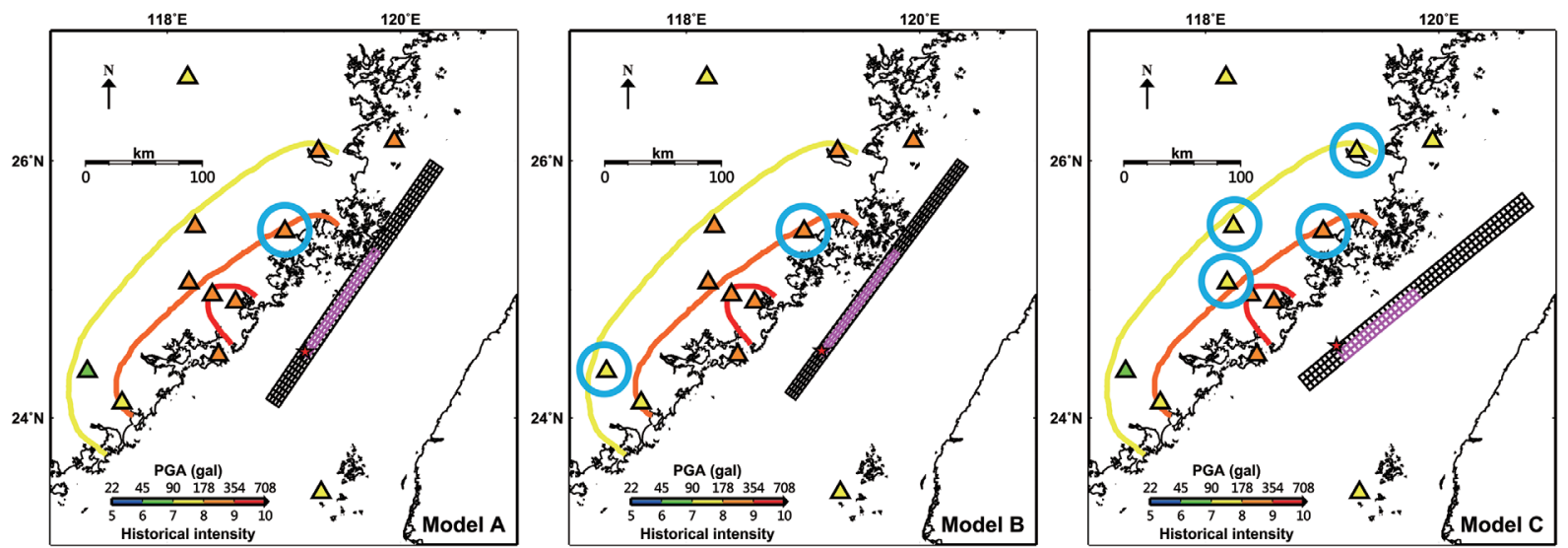

Fig. 5. The same as Fig. 4, but, for the fault model with heterogeneous slip of one asperity (the subfaults in pink) with focal mechanisms of Model A with 200 subfaults, Model B with 200 subfaults, and Model C with 150 subfaults. The red asterisk indicates the epicenter of 1604 Quanzhou earthquake of from Huang et al. (2006). The contour lines present the historical intensity distribution with the comparison of the simulated intensity for the stations (tringles with color correspond to the intensity) for the towns literature stated intensity for an average stress drop of $10 \mathrm{MPa}$. The stations with a blue circle around are those who match the value of the literature intensity shown in Fig. 2 . The corresponding historical intensity with PGA values for target stations in Taiwan Strait are also shown. 
and lower intensity away from the location of the asperity, although no station reaches an intensity 9 in any model. We also marked the matching stations in Fig. 5. Although only small number of stations can match the reported intensity, Model $\mathrm{C}$ has most matching stations among the three models. With limited information on the scaling of the historical intensity to PGA and possible local site effects, it is difficult to evaluate which focal mechanism of Models A, B, and $\mathrm{C}$ is the best. If we consider only a simple comparison in simulated and historical intensities, Model C might provide the best focal mechanism for its better explanation of the historical intensities. Furthermore, heterogeneous slip models with more concentrated high-amplitude slip and higher stress drops near Quanzhou are necessary to reach intensity 9. However, due to uncertainties on PGA scaling to historical intensities and limited information of local site effects, we do not intend to make further comparisons. The comparisons above simply suggest that the 1604 Quanzhou earthquake required a fault model with a heterogeneous slip distribution and a comparatively large slip of at least 16 $21 \mathrm{~m}$, and an average stress drop of about $10 \mathrm{MPa}$. With these settings, the 1604 Quanzhou earthquake would have had a magnitude of 8.1.

The pattern of the simulated intensities from all models shows that the reported intensities have similar values in the northeastern and southwestern regions, while the simulated intensities are slightly higher in the northeastern than southwestern sites. In the simulation, we set up the position of the fault according to the fault trace shown in Fig. 2, and the epicenter is placed at the southern part of the fault. The combination of fault position and directivity might explain the higher intensities to the northeast than southwest of Quanzhou. It is possible that the true position of the fault and asperity was further southwest than the position used in the models.

\subsection{Synthetic Hybrid Acceleration Waveforms and Response Spectra}

To justify the synthetic hybrid accelerations waveforms, we compared the synthetic response spectra of the three stations in the Taiwan Strait to the response spectra derived from NGA-East (PEER 2015) and those from crustal earthquakes in Taiwan (Lin et al. 2012). The three-component synthetic hybrid acceleration waveforms for three target stations (HUA, MAT, KIN) in the Taiwan Straits for stress drops of 3 and $10 \mathrm{MPa}$, and the $10 \mathrm{MPa}$ model with asperity are shown in Figs. S1 to S3 (supplementary file), respectively. The waveforms obtained for the models from three focal mechanisms (A, B, and C) are similar, with only minor differences in amplitude. We calculated the response spectra with 5\% damping ratio of the two horizontal synthetic waveforms of the proposed models, then took their geometric mean to compare with the GMPE predicted ones. Figure 6 shows the acceleration response spectra of three Taiwan Strait stations (HUA, MAT, KIN) with stress drops of 3 and $10 \mathrm{MPa}$, and $10 \mathrm{MPa}$ with a single asperity for Model C. Similar comparisons for Models A and B are shown in the supplementary materials as Figs. S4 and S5, respectively. The response spectra derived from NGAEast (PEER 2015) and the crustal earthquakes in Taiwan (Lin et al. 2012) were also shown for comparison with their corresponding magnitudes and distances. The simulated response spectra of all models in higher frequency (>0.4 Hz) component has similar pattern with Taiwanese crustal earthquakes. For the longer period motion with frequencies less than $0.4 \mathrm{~Hz}$, the simulated response spectra are larger than the derived response spectra of NGA-East and Taiwanese crustal earthquakes. The reason for this discrepancy is possibly due to the general problem for the lack of the observations in long period motion used in the GMPEs
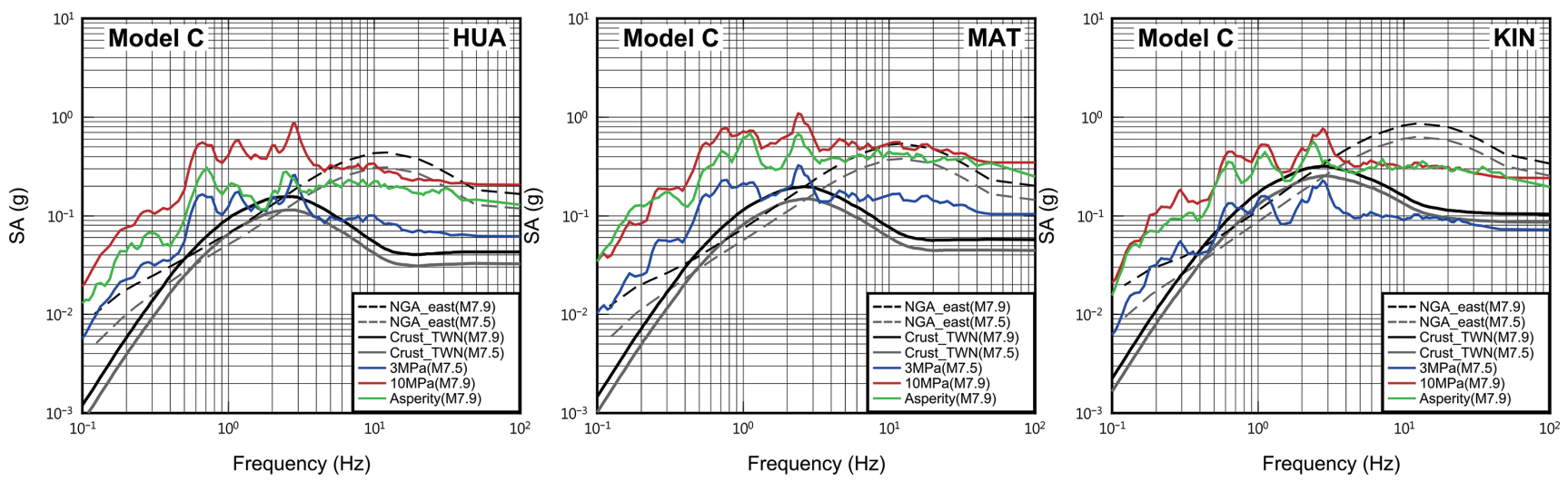

Fig. 6. The acceleration response spectrum comparisons of three Taiwan Strait stations HUA, MAT, and KIN for Model C. The response spectra are for the homogeneous slip models of stress drop of $3 \mathrm{MPa}$ (blue) and $10 \mathrm{MPa}$ (red), and the heterogeneous one asperity for an average stress drop of $10 \mathrm{MPa}$ (green). The derived response spectra from NGA-East (dashed lines) and those from Taiwan crustal earthquakes (solid lines) for the corresponding magnitudes with smaller magnitudes in gray and larger magnitude in black are also shown. 
of both NGA-East and Taiwanese crustal earthquakes. The GMPE model for Taiwanese crustal earthquakes include events with magnitude only up to $\mathrm{M}_{\mathrm{w}}$ 7.6, which is the magnitude of the largest crustal event (the 1999 Chi-Chi earthquake) in Taiwan. Although the GMPE model of NGA-East considered the range of magnitude from 5.0 to 8.0 in their study, the model was obtained by scaling the ground motions in the NGA-West2 GMPEs (Boore et al. 2013) with regional modification factors from hybrid ground motion simulation. The range of magnitude in the NGA-West2 GMPEs is up to M 7.9 (the 2008 Wenchuan earthquake). However, this comparison draws attention to the generation of long period motions for an event of this magnitude, and, thus, the importance of the seismic hazard assessment for the long period motions in this region. Although with large uncertainties in the models, this comparison suggests the possible generation of long period motions in most of the stations. For the station HUA, closest to Taiwan, the response spectra show that spectral acceleration with a period of about 2 seconds could be up to $0.2-0.3 \mathrm{~g}$. It is therefore necessary to consider ground motion for an event of this kind in the Taiwan Strait for long-period seismic hazard analysis in western Taiwan. Despite the uncertainties for historical earthquake, our results highlight the importance of including the western offshore faults into seismic hazard assessments for Taiwan, especially for long-period motion.

\subsection{Potential Tsunami Hazard}

According to the historical literature, no tsunami damage but only the disturbance of the local sea level at the southeast coast of China was reported. The only disturbance of sea level along the coast of Taiwan associated with the 1604 Quanzhou earthquake was near the coast of Hsinchu, Taiwan, with a reported tsunami height of about $0-1 \mathrm{~m}$ (Ye et al. 1993). Ma and Lee (1997) considered an event offshore northwestern Taiwan with reverse faulting (strike: 240, dip: 30, rake: 90 ) to evaluate the possible maximal tsunami height near the coast of Hsinchu. Their results showed that the maximal tsunami height could reach about 0.2 and $1 \mathrm{~m}$ near the coast of Hsinchu for events of $\mathrm{M}_{\mathrm{w}} 7.5$ and 8.0 , respectively, from the events in southeastern coast of China (northwestern offshore of Taiwan). Wu et al. (2015) found the maximum tsunami height of about $0.3 \mathrm{~m}$ at the coast of Hsinchu using a source model similar to Model B with magnitude of $M_{w}$ 7.9. The estimated tsunami heights from Ma and Lee (1997) and Wu et al. (2015) are similar to the recorded disturbance of the sea surface in 1604. The tsunami height of the 1604 Quanzhou earthquake can be up to $100 \mathrm{~cm}$ if its focal mechanism is closer to reverse type. According to section 6.1, the comparison of the simulated intensity with the literature intensity suggests the focal mechanism of the 1604 Quanzhou earthquake is more similar to a pure strike-slip type mechanism. Considering that the strike-slip fault systems usually produce smaller vertical displacement of the seafloor than reverse faults, the tsunami height of the 1604 Quanzhou earthquake might be smaller than $100 \mathrm{~cm}$. However, further studies for tsunami hazard from large earthquakes in the Taiwan Strait are necessary due to the uncertainties of the literature intensity of the 1604 Quanzhou earthquake.

\section{CONCLUSION}

From the comparison of the simulated intensities to historical intensities, the waveform simulations suggest that the 1604 earthquake has a fault rupture with localized large slip of $16-20 \mathrm{~m}$ (asperity), with an average stress drop of $10 \mathrm{MPa}$ and a magnitude $\mathrm{M}_{\mathrm{w}}$ 8.1. Due to the uncertainties in scaling of the historical intensity to modern PGA, and limited information on possible site effects on ground motions, our study focuses on the compilation of the historic literature and past studies of the 1604 earthquake with basic rupture modeling using hybrid waveform modeling. The comparison of the simulated response spectra to that from GMPEs suggests that this earthquake will result in a larger long period motion $(<0.4 \mathrm{~Hz})$ to Taiwan compared to that from the regional crustal earthquakes. The large long-period motions bring the attention to the seismic hazard assessment across the Taiwan Strait for the metropolitans with dense population.

\section{DATA AND RESOURCES}

The historical documents stated in this study is from the archive of Department of Earthquake Disaster Prevention, China Earthquake Administration (DEDP 1995) for the Directory of historical strong earthquakes in China from 23rd Century B.C. to 1991 A.D. The historical intensity scale is from General Administration of Quality Supervision, Inspection and Quarantine of the P. R. C. and Standardization Administration of the P. R. C. (GAQSIQ and SAC 2008) for the study of the Chinese seismic intensity scale.

Acknowledgements We thank Sebastian von Specht for his valuable comments to improve the quality of the paper. We also thank two anonymous reviewers for their comments to improve the structure of the paper. This work is supported by "Earthquake-Disaster \& Risk Evaluation and Management Center, E-DREaM" from The Featured Areas Research Center Program within the framework of the Higher Education Sprout Project by the Ministry of Education (MOE) in Taiwan. This research is also supported under Taiwan Earthquake Model of the Taiwan Earthquake Research Center (TEC), funded through the Ministry of Science and Technology (MOST) with grant number MOST 
108-2116-M-008-025-MY2. The TEC contribution number for this article is 00171 . This paper is also supported by the URBASIS project, an European Union's H2020-MSCAITN-2018 project (grant agreement No 813137).

\section{REFERENCES}

Allmann, B. P. and P. M. Shearer, 2009: Global variations of stress drop for moderate to large earthquakes. J. Geophys. Res., 114, doi: 10.1029/2008jb005821. [Link]

Atkinson, G. M. and D. M. Boore, 1998: Evaluation of models for earthquake source spectra in eastern North America. Bull. Seismol. Soc. Am., 88, 917-934.

Boore, D. M., 1983: Stochastic simulation of high-frequency ground motions based on seismological models of the radiated spectra. Bull. Seismol. Soc. Am., 73, 18651894.

Boore, D. M., J. P. Stewart, E. Seyhan, and G. M. Atkinson, 2013: NGA-West2 Equations for Predicting Response Spectral Accelerations for Shallow Crustal Earthquakes, PEER Report 2013/05, Pacific Earthquake Engineering Research Center, $142 \mathrm{pp}$.

Cai, H.-T., H. Kuo-Chen, X. Jin, C.-Y. Wang, B.-S. Huang, and H.-Y. Yen, 2015: A three-dimensional Vp, Vs, and $\mathrm{Vp} / \mathrm{Vs}$ crustal structure in Fujian, Southeast China, from active- and passive-source experiments. J. Asian Earth Sci., 111, 517-527, doi: 10.1016/j. jseaes.2015.06.014. [Link]

Chen, K.-X., H. Kuo-Chen, D. Brown, Q. Li, Z. Ye, W.-T. Liang, C.-Y. Wang, and H. Yao, 2016: Three-dimensional ambient noise tomography across the Taiwan Strait: The structure of a magma-poor rifted margin. Tectonics, 35, 1782-1792, doi: 10.1002/2015tc004097. [Link]

Cheng, S.-N., J. H. Jiang, and Y.-L. Chen, 2011: Establishment of historical earthquake in Taiwan region. Technique Report of Central Weather Bureau, MOTCCWB-100-E-14, Central Weather Bureau, Taipei City, Taiwan, 427-448. (in Chinese)

DEDP (Department of Earthquake Disaster Prevention, China Earthquake Administration), 1995: Directory of Historical Strong Earthquakes in China (23rd Century B.C. - 1991 A.D.), Seismological Press, Beijing, 514 pp. (in Chinese)

Ding, X., P. Wang, and Y. Xie, 1989: Analysis on basic parameters of earthquake in coastal southern Fujian on March 28, 1906. Journal of Oceanography in Taiwan Strait, 1, 40-47. (in Chinese)

GAQSIQ and SAC (General Administration of Quality Supervision, Inspection and Quarantine of the P. R. C. and Standardization Administration of the P. R. C.), 2008: The Chinese seismic intensity scale (GB/T 17742-2008), Standards Press of China, Beijing. (in Chinese)
Guo, H., J. Lin, S. Chen, Y. Huang, W. Xie, J. Wang, X. Chen, and Q. Ouyang, 2015: Analysis of Influence of Fujian and Taiwan Destructive Earthquake in Quanzhou Area. Open Journal of Nature Science, 3, 247261, doi: 10.12677/ojns.2015.34030. (in Chinese) [Link]

Huang, Z. and S. Wang, 2006: Tectonic features and activity of Binhai fault zone in Taiwan Strait. Journal of Geodesy and Geodynamics, 26, 16-22. (in Chinese)

Huang, Z., S. Wang, and X. Wang, 2006: Analysis of the 1604 Quanzhou offshore earthquake-tsunami effects. Earthquake, 26, 94-102. (in Chinese)

Irikura, K., 2004: Recipe for predicting strong ground motion from future large earthquake. Annuals of Disaster Prevention Research Institute, 47A, 25-45. (in Japanese)

Irikura, K. and H. Miyake, 2001: Prediction of strong ground motions for scenario earthquakes. Journal of Geography (Chigaku Zasshi), 110, 849-875, doi: 10.5026/ jgeography.110.6_849. (in Japanese) [Link]

Kanamori, H. and D. L. Anderson, 1975: Theoretical basis of some empirical relations in seismology. Bull. Seismol. Soc. Am., 65, 1073-1095.

Lee, Y.-T., K.-F. Ma, M.-C. Hsieh, Y.-T. Yen, and Y.-S Sun, 2016: Synthetic ground-motion simulation using a spatial stochastic model with slip self-similarity: Toward near-source ground-motion validation. Terr. Atmos. Ocean. Sci., 27, 397-405, doi: 10.3319/ TAO.2015.11.27.01(TEM). [Link]

Lin, P. S., P. S. Hsie, Y. R. Lee, C. T. Cheng, and K. S. Shao, 2012: The Research of Probabilistic Seismic Hazard Analysis and Geological Survey of Nuclear Power Plant: Construction of Ground Motion Prediction Equation for Response Spectra. Commission Report of the Institute of Nuclear Energy Research, Atomic Energy Council, Executive Yuan. (in Chinese)

Ma, K.-F. and M.-F. Lee, 1997: Simulation of historical tsunamis in the Taiwan region. Terr. Atmos. Ocean. Sci., 8, 13-30, doi: 10.3319/TAO.1997.8.1.13(T). [Link]

Motazedian, D. and G. M. Atkinson, 2005: Stochastic finite-fault modeling based on a dynamic corner frequency. Bull. Seismol. Soc. Am., 95, 995-1010, doi: 10.1785/0120030207. [Link]

PEER (Pacific Earthquake Engineering Research Center), 2015: NGA-East: Median Ground-Motion Models for the Central and Eastern North America Region, PEER Report No. 2015/04, Pacific Earthquake Engineering Research Center, 351 pp.

Roumelioti, Z. and I. A. Beresnev, 2003: Stochastic finite-fault modeling of ground motions from the 1999 Chi-Chi, Taiwan, earthquake: Application to rock and soil sites with implications for nonlinear site response. Bull. Seismol. Soc. Am., 93, 1691-1702, doi: 10.1785/0120020218. [Link] 
Somerville, P., K. Irikura, R. Graves, S. Sawada, D. Wald, N. Abrahamson, Y. Iwasaki, T. Kagawa, N. Smith, and A. Kowada, 1999: Characterizing crustal earthquake slip models for the prediction of strong ground motion. Seismol. Res. Lett., 70, 59-80, doi: 10.1785/ gssrl.70.1.59. [Link]

Sun, J., H. Xu, W. Zhan, and J. Cao, 2012: Activity and triggering mechanism of seismic belt along the northern South China Sea continental margin. Journal of Tropical Oceanography, 31, 40-47.

Wells, D. L. and K. J. Coppersmith, 1994: New empirical relationships among magnitude, rupture length, rupture width, rupture area, and surface displacement. Bull. Seismol. Soc. Am., 84, 974-1002.

Wu, T.-R., J.-X. Zhang, Z.-Y. Lin, and Z.-W. Liao, 2015: Impact Intensity Analysis on the 1604 Quanzhou Earthquake Tsunami and the Impacts to the Western Coast of Taiwan. Technique Report of Central Weather Bureau, MOTC-CWB-104-E-19, Central Weather Bureau, Taipei City, Taiwan, 710-752. (in Chinese)

Wu, W., 1988: The 1604 Fujian-Quanzhou M8.0 Earthquake, Seismological Press, 182-191. (in Chinese)

Xie, Y., 1992: Histortical seismicity of the offshore FujianGuangdong region. Acta Seismol. Sin., 5, 635-646, doi: 10.1007/BF02650557. [Link]

Xie, Y. and M. Cai, 1985: Compilation of Historical Mate- rials of Chinese Earthquakes (Vol. II), Science Press, Beijing.

Ye, L., X. Wang, and C. Bao, 1993: Tsunami in the China Seas and its warning service. Proc. IUGG/IOC International Tsunami Symposium, 771-778.

Zhan, W., Z. Sun, C. Tang, J. Zhu, and L. Sun, 2004: Littoral active fault belt of south China and its control on seismic activity in Taiwan Strait. Journal of Tropical Oceanography, 23, 19-24. (in Chinese)

Zhang, S., 1981: The 1604 M8.0 Quanzhou mega earthquake. South China Journal of Seismology, 00, 54-59. (in Chinese)

Zhang, Y., H. Yao, H.-Y. Yang, H.-T. Cai, H. Fang, J. Xu, X. Jin, H. Kuo-Chen, W.-T. Liang, and K.-X. Chen, 2018: 3-D Crustal Shear-Wave Velocity Structure of the Taiwan Strait and Fujian, SE China, Revealed by Ambient Noise Tomography. J. Geophys. Res., 123, 8016-8031, doi: 10.1029/2018jb015938. [Link]

Zhang, Y., H. Kuo-Chen, J. Alvarez-Marron, D. Brown, A. T.-S. Lin, Z. Xie, and X. Jin, 2020: Imaging active faulting in the western Taiwan Strait. Sci.Rep., 10, doi: 10.1038/s41598-020-60666-3. [Link]

Zhu, L. and L. A. Rivera, 2002: A note on the dynamic and static displacements from a point source in multilayered media. Geophys. J. Int., 148, 619-627, doi: 10.1046/j.1365-246x.2002.01610.x. [Link] 